\title{
Selective adrenal venous sampling is not always useful in primary aldosteronism (PA)
}

\section{Endocrinology and Interventional Radiology Department. Bilbao, Spain}

\section{EP-34}

\section{Hospital de Basurto}

\section{OBJECTIVES}

Adrenal venous sampling (AVS) is regarded as the gold-standard for the study of lateralization of PA. After catheterization of both adrenal veins, confirmed by ratio of [cortisol] in each adrenal vein and peripheral vein (selectivity index, SI), we accept lateralization if ratio Aldosterone /Cortisol (A/C) between both adrenal veins is over 3-4 (lateralization index, LI), particularly if non-dominant vein has $A / C$ level lower than peripheral vein.

Repeated sampling is a usual procedure to increase the chance of successful AVS. Although optimal selectivity, eventually analytical results are difficult to explain.

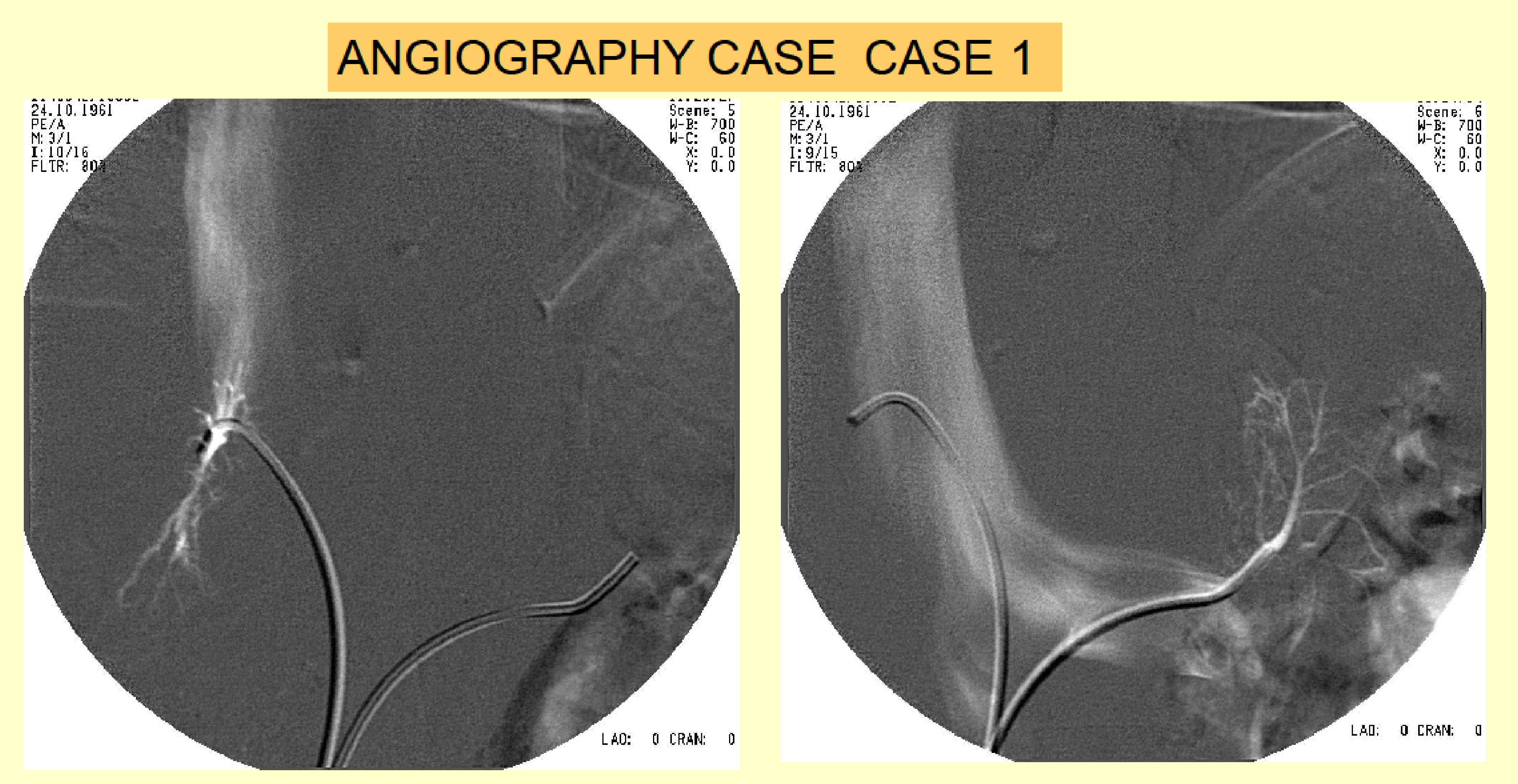

Case 2 - A 70-year-old female suffered from hypertension and hypokalemia for 10 years before admission. RAR: 155 and 227. Plasma ALDO after 2L IV physiologic fluid: $53.2 \mathrm{ng} / \mathrm{dl}$. Samples from both adrenal veins showed good SI (right: 10,8; left: 15.3) but bilateral ALDO suppression (Table 2). CT scan showed normal adrenal glands. Optimal control was achieved in response to spironolactone, $100 \mathrm{mg}$ daily.

\begin{tabular}{c|ccc} 
Case 2 & PERIPHERAL & RIGHT ADRENAL & LEFT ADRENA \\
\hline ALDO & 290 & 795 & 526 \\
\hline CORTISOL & 4,03 & 43,66 & 61,73 \\
DO/CORTISOL & $\mathbf{7 1 , 9 6}$ & $\mathbf{1 8 , 2 1}$ & $\mathbf{8 , 5 2}$ \\
\hline ECTIVITY INDEX (SI) & $\mathbf{1 0 , 8 3}$ & $\mathbf{1 5 , 3 2}$ \\
\hline
\end{tabular}

Table 2 - Results of the selective samples

These two cases illustrate potential inaccuracies of AVS. These are probably due to superselective canalization of adrenal veins, not draining venous effluent of the tumor producing aldosterone excess. In both cases, right SI were very high. These high ratios have been proposed as suggestive of very selective sampling, collecting blood of suppressed adrenal tissue, but not from the adenoma. Another possibility in the second case is an anomalous drainage of pathologic tissue, by accessories veins not canulated in AVS or extraadrenal production of aldosterone.

\section{CONCLUSIONS}

We present two cases of PA with selective AVS, but puzzling results about lateralization. We discuss potential mechanism of these results and call attention to the occurrence of this problem.

\section{RESULTS}

Case 1 - A 52-year-old female was studied for severe hypertension for two years. She showed high ratio ALDO/PRA (RAR: 62,5 ) and urinary ALDO of $16,4 \mu \mathrm{g} / 24 \mathrm{~h}$ with high urinary sodium (340 mEq). First samples (Table 1) with optimal SI (right: 44.3 and left: 12.2), suggested bilateral production (LI: 1.12 ) with both adrenal $A / C$ levels higher than peripheral vein. Second samples five minutes later, also were selective (right SI: 18.9 and left SI: 10.3), with right lateralization (LI: 3,2), coincident with adrenal tumor in $C T$, and an $A / C$ ratio in left vein lower than peripheral $A / C$ ratio. After right adrenalectomy, mean BP was reduced $30 / 18 \mathrm{~mm} \mathrm{Hg}$ from previously, RAR was normal and histology showed $15 \mathrm{~mm}$ left adenoma.

\begin{tabular}{|c|c|c|c|}
\hline First sample & PERIPHERAL & RIGHT ADRENAL & LEFT ADRENAL \\
\hline ALDO $(\mathrm{ng} / \mathrm{ml})$ & 222 & 21546 & 5295 \\
\hline CORTISOL $(\mu \mathrm{g} / \mathrm{dl})$ & 29,95 & 1328 & 364,6 \\
\hline ALDO/CORTISOL & 7,41 & 16,22 & 14,52 \\
\hline SELECTIVITY INDEX (SI) & $\mathbf{4 4 , 3 4}$ & $\mathbf{1 2 , 1 7}$ \\
\hline
\end{tabular}

\begin{tabular}{ccccc|}
\hline LATERALIZATION & $\mathbf{1 , 1 1 7 1 7 0 0 4}$ & BILATERAL & \\
\hline Second sample & PERIPHERAL & RIGHT ADRENAL & LEFT ADRENAL \\
\hline ALDO & 209 & 8198 & 1400 \\
CORTISOL & 30,83 & 582,2 & 316,8 \\
\hline ALDO/CORTISOL & 6,78 & 14,08 & 4,42 \\
\hline
\end{tabular}

SELECTIVITY INDEX (SI)

18,88

10,28

\section{LATERALIZATION $3,18634539 \quad$ RIGHT ADRENAL}

Table 1 - Results of two consecutive simultaneous samples in first case

\section{Reference}

Zelinka T. et al. Kidney Blood Press Res 2012; 35: 205-210. Discrepant results of adrenal venous sampling in seven patients with primaty aldosteronism.

doi: $10.1159 / 000330720$ 